\title{
An NMR study of macromolecular aggregation in a model polymer-surfactant solution
}

\author{
Suliman Barhoum ${ }^{\mathrm{a})}$ and Anand Yethiraj ${ }^{\mathrm{b})}$ \\ Department of Physics and Physical Oceanography, Memorial University, St. John's, \\ Newfoundland and Labrador A1B 3X7, Canada
}

(Received 4 November 2009; accepted 17 December 2009; published online 13 January 2010)

\begin{abstract}
A model complex-forming nonionic polymer-anionic surfactant system in aqueous solution has been studied at different surfactant concentrations. Using pulsed-field-gradient diffusion NMR spectroscopy, we obtain the self-diffusion coefficients of poly(ethylene glycol) (PEO) and sodium dodecyl sulfate (SDS) simultaneously and as a function of SDS concentration. In addition, we obtain NMR relaxation rates and chemical shifts as a function of SDS concentration. Within the context of a simple model, our experimental results yield the onset of aggregation of SDS on PEO chains $(\mathrm{CAC}=3.5 \mathrm{mM})$, a crossover concentration $\left(\mathrm{C}_{2}=60 \mathrm{mM}\right)$ which signals a sharp change in relaxation behavior, as well as an increase in free surfactant concentration and a critical concentration $\left(\mathrm{C}_{\mathrm{m}}=145 \mathrm{mM}\right)$ which signals a distinct change in diffusion behavior and a crossover to a solution containing free micelles. $\mathrm{C}_{\mathrm{m}}$ also marks the concentration above which obstruction effects are definitely important. In addition, we obtain the concentration of SDS in monomeric form and in the form of free micelles, as well as the average number of SDS molecules in a PEO-SDS aggregate $\left(\mathrm{N}_{\mathrm{Aggr}}\right)$. Taken together, our results suggests continuous changes in the aggregation phenomenon over much of the concentration but with three distinct concentrations that signal changes in the nature of the aggregates. (C) 2010 American Institute of Physics.
\end{abstract}

[doi:10.1063/1.3290985]

\section{INTRODUCTION}

Multicomponent solutions consisting of polymers, surfactants, proteins, and other macromolecules are common to many biological systems as well as cosmetic and pharmaceutical preparations. ${ }^{1-3}$ The understanding of the nature of macromolecular aggregates and complexes is consequently of great technological relevance. The poly(ethylene oxide) (PEO)-sodium dodecyl sulfate (SDS) polymer-surfactant system in aqueous solution is a useful model system for the study of macromolecular complex formation.

A quantitative study of complex formation in the PEOSDS system is a starting point to study more complex biological systems with crowded environments, e.g., cellular environments composed of different kinds of macromolecules at high concentration. ${ }^{4-6}$ Diffusion processes in cells are likely to be strongly influenced by macromolecular crowding effects. ${ }^{7,8}$

In spite of the wealth of knowledge about the PEO-SDS system $^{3,9,10}$ (summarized in Sec. II), important questions have only partial answers. Are SDS conformations in the surfactant-polymer aggregate quantitatively different from those in the SDS micelle? Where in the aggregation regime do free micelles also form (and is there a distinct transition)? When do crowding effects become important? The partitioning of the SDS concentration between the monomeric state, the surfactant-polymer aggregate, and free micelles as a

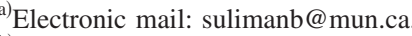

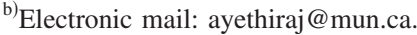

function of total SDS concentration remains unquantified. In this study we use NMR spectroscopy to address these questions with high experimental precision.

\section{BACKGROUND}

The interaction between PEO and SDS molecules in aqueous solution has been studied by many researchers. ${ }^{11-19}$ We summarize below, briefly, what is known via a variety of techniques ${ }^{11,12,14-22}$ including NMR relaxometry ${ }^{11,23,24}$ and diffusometry. $10,12,18,19,25$

1. The critical micelle aggregation (CMC) is a critical concentration above which SDS micelles begin to form in a pure surfactant solution. ${ }^{26,27}$ SDS micelles have been shown in a neutron scattering study to be best fit to an oblate ellipsoid shape (or a disklike shape) at $\mathrm{C}^{\mathrm{SDS}} \approx 39 \mathrm{mM}$, with half axes $\mathrm{a}=12 \mathrm{~A}^{\circ}$ and $\mathrm{b}$ $=20.3 \mathrm{~A}^{\circ}$. $^{28}$

2. The critical concentration above which PEO-SDS aggregates begin to form ${ }^{12,15,18,20,25}$ is called the critical aggregation concentration (CAC).

3. There is a second higher SDS concentration termed as $\mathrm{C}_{2}$ that signals a change in the nature of the PEO-SDS aggregates. This has been identified either as the concentration where free micelles coexist with PEO-SDS aggregates $^{13-15}$ or the concentration that signals the saturation in the number of SDS molecules $\mathrm{N}_{\text {Aggr }}$ that aggregate on a PEO molecule ${ }^{13,29}$ (the notation $\mathrm{C}_{\mathrm{m}}$ has been employed for the former to distinguish it from $\left.\mathrm{C}_{2}\right) .{ }^{17}$ Pulsed gradient spin echo NMR spectroscopy 
TABLE I. CAC values for PEO-SDS system (Refs. 11, 12, and 16-19) using NMR, conductivity measurements and isothermal titration calorimetry (ITC).

\begin{tabular}{|c|c|c|c|c|c|}
\hline Experiment & $\begin{array}{c}\text { PEO } \\
\mathrm{M}_{\mathrm{w}}(\mathrm{g} / \mathrm{mole})\end{array}$ & $\begin{array}{c}\text { PEO Conc. } \\
(\% \mathrm{w} / \mathrm{v})\end{array}$ & $\begin{array}{c}\mathrm{T} \\
\left({ }^{\circ} \mathrm{C}\right)\end{array}$ & $\begin{array}{l}\text { CAC } \\
(\mathrm{mM})\end{array}$ & $\begin{array}{c}\mathrm{C}_{2} \\
(\mathrm{mM})\end{array}$ \\
\hline $\mathrm{NMR}^{\mathrm{a}}$ & 300000 & $\approx 0.2$ & 20 & 4.5 & $\ldots$ \\
\hline Conductivity ${ }^{\mathrm{b}}$ & 20000 & 0.2 & 25 & 4.5 & $\ldots$ \\
\hline ITC $^{\mathrm{c}}$ & 20000 & $\approx 0.1$ & 25 & $\approx 4.4$ & $\ldots$ \\
\hline $\mathrm{NMR}^{\mathrm{d}}$ & 20000 & $\approx 0.2$ & 25 & $\approx 5.7$ & $15-25$ \\
\hline $\mathrm{NMR}^{\mathrm{e}}$ & 4000 & 0.2 & 25 & 3.3 & $\ldots$ \\
\hline $\mathrm{NMR}^{\mathrm{f}}$ & 20000 & $\approx 0.2$ & 25 & 4.6 & $\ldots$ \\
\hline $\begin{array}{l}{ }^{\mathrm{a}} \text { Reference } 11 . \\
{ }^{\mathrm{b}} \text { Reference } 16 . \\
{ }^{\mathrm{c}} \text { Reference } 17 .\end{array}$ & & $\begin{array}{l}{ }^{\mathrm{e}} \mathrm{Re} \\
{ }^{\mathrm{f}} \mathrm{Re}\end{array}$ & $\begin{array}{l}12 . \\
18 . \\
19 .\end{array}$ & & \\
\hline
\end{tabular}

has been used ${ }^{10}$ to measure the self-diffusion coefficient of PEO molecules at different SDS concentrations: progressive changes in the values of the PEO diffusion coefficients with increasing concentrations were observed, attributed to the aggregation of SDS molecules on PEO molecules, the saturation of the polymer molecules with surfactant, and the transition of SDS micelles from sphere to rodlike micelles, respectively. ${ }^{24}$

4. Finally, a nonmonotonic viscosity maximum has been observed at SDS concentration near or above $\mathrm{C}_{2} \cdot{ }^{23,30}$ While small angle neutron scattering has provided strong evidence for the SDS aggregating on the polymer in the form of micelle subunits, ${ }^{13}$ the nature of the surfactant-polymer interaction is not yet clear.

Table I shows the values of CAC for the PEO-SDS system in aqueous solution that have been measured using different techniques. For the purpose of comparison, we converted some CAC concentration values from mass percentage (weight percent) to molar concentration (C) using ${ }^{19} \mathrm{C}=\left[\rho_{\mathrm{D}_{2} \mathrm{O}} / \mathrm{M}_{\mathrm{s}}\right][\mathrm{wt} \% /(100-\mathrm{wt} \%)]$, where $\rho_{\mathrm{D}_{2} \mathrm{O}}$ and $\mathrm{M}_{\mathrm{s}}$ are the density of deuterium oxide (in $\mathrm{g} / \mathrm{L}$ ) and the molecular mass of surfactant, respectively. There is a spread of about $30 \%$ in both the CAC and $\mathrm{C}_{2}$ values reported.

NMR spectroscopy has been used as a powerful technique to study macromolecular dynamics ${ }^{31}$ in polymersurfactant systems (and the PEO-SDS system in particular) since it can report on molecular motion inside the aqueous solutions via the longitudinal relaxation time $T_{1}$ and the transverse relaxation time $\mathrm{T}_{2}{ }^{11,32}$ In addition, pulsed-fieldgradient diffusion NMR spectroscopy is used to measure the molecular self-diffusion coefficient. ${ }^{33,34}$ All of these physical quantities will change due to the interaction between molecules, molecular aggregation, and micellization. ${ }^{35}$

A key feature of the current study is the simultaneous measurement of diffusion coefficient of SDS, PEO, and DOH components, in addition to relaxation rates, in samples that span the entire concentration range from below the CAC to just below the sphere-rod transition. The simultaneous measurement of diffusion coefficients of all components allows us to pinpoint the different regimes quantitatively, to establish regimes of absolute validity of a simple model, and to make a strong quantitative statement in the same system about the $\mathrm{CAC}$, the saturation concentration $\mathrm{C}_{2}$, and the micellization concentration $\mathrm{C}_{\mathrm{m}}$.

\section{EXPERIMENTAL}

PEO with 20000 average molecular mass and SDS ( $>99 \%$ purity) with 288.38 average molecular mass were purchased from Sigma-Aldrich Canada and were used as received without purification. The PEO chain in the study has $\approx 450$ monomers (each of length $\approx 0.44 \mathrm{~nm}$ ). The Kuhn length $\ell_{\mathrm{k}} \approx 1.8 \mathrm{~nm}^{36}$ Deuterium oxide $\mathrm{D}_{2} \mathrm{O}$ with $99.9 \%$ isotopic purity was purchased from Cambridge Isotope Laboratories.

We prepared three different solutions: $\mathrm{PEO}(0.5 \% \mathrm{w} / \mathrm{v}) / \mathrm{D}_{2} \mathrm{O}, \quad \operatorname{SDS}(455 \mathrm{mM}) / \mathrm{PEO}(0.5 \% \mathrm{w} / \mathrm{v}) /$ $\mathrm{D}_{2} \mathrm{O}$, and $\operatorname{SDS}(794 \mathrm{mM}) / \mathrm{PEO}(0.5 \% \mathrm{w} / \mathrm{v}) / \mathrm{D}_{2} \mathrm{O}$. Samples with SDS concentration below $455 \mathrm{mM}$ were prepared by mixing $\mathrm{PEO}(0.5 \% \mathrm{w} / \mathrm{v}) / \mathrm{D}_{2} \mathrm{O}$ stock solution with $\mathrm{SDS}(455 \mathrm{mM}) / \mathrm{PEO}(0.5 \% \mathrm{w} / \mathrm{v}) / \mathrm{D}_{2} \mathrm{O}$ stock solution, while we used $\operatorname{SDS}(794 \mathrm{mM}) / \mathrm{PEO}(0.5 \% \mathrm{w} / \mathrm{v}) / \mathrm{D}_{2} \mathrm{O}$ stock solution to prepare the samples with SDS concentrations larger than $455 \mathrm{mM}$.

The one-dimensional (1D) proton NMR spectrum has been observed for different species in all samples at a resonance frequency of $600 \mathrm{MHz}$ on a Bruker Avance II spectrometer.

Figure 1 shows six broad and well-separated peak regions related to this system. Peak 1 is the $\mathrm{DOH}$ peak created due to the quick exchange of protons between $\mathrm{D}_{2} \mathrm{O}$ and $\mathrm{H}_{2} \mathrm{O}$ molecules in solution. Peaks 2 and 4-6 are associated with the protons of SDS molecule SDS1, SDS2, SDS3, and SDS4 as shown in Fig. 1. Peak 3 is associated with the protons of the PEO molecule. The $1 \mathrm{D}$ spectrum of the SDS $/ \mathrm{D}_{2} \mathrm{O}$ system similarly includes only five peak regions because it is polymer-free. All NMR experiments were performed at T $=298 \mathrm{~K}$.

The self-diffusion measurements were carried out in a diffusion probe (Diff 30) and with maximum field gradient $(1800 \mathrm{G} / \mathrm{cm})$. Diffusion was measured with a pulsed-fieldgradient stimulated-echo sequence ${ }^{33}$ with (almost square) trapezoidal gradient pulses. The diffusion coefficient of a molecule in aqueous solution is obtained from the attenuation of the signal according to the equation ${ }^{33}$ 




FIG. 1. 1D ${ }^{1} \mathrm{H}-\mathrm{NMR}$ spectrum for $\mathrm{PEO}(0.5 \% \mathrm{w} / \mathrm{v}) / \mathrm{SDS}(455 \mathrm{mM}) / \mathrm{D}_{2} \mathrm{O}$ sample at a sample temperature $298 \mathrm{~K}$. Inset: the chemical formula of SDS molecule.

$$
\ln \left(\frac{\mathrm{S}(\mathrm{k})}{\mathrm{S}(0)}\right)=-\mathrm{Dk}
$$

where $\mathrm{S}(\mathrm{k})$ is the "intensity" of the signal (the integration of the relevant peak region) in the presence of field gradient pulse, $\mathrm{S}(0)$ is the intensity of the signal in the absence of field gradient pulse, $\mathrm{k}=(\gamma \delta \mathrm{g})^{2}(\Delta-\delta / 3)$ is a generalized gradient strength parameter, $\gamma=\gamma^{\mathrm{H}}=2.6571 \times 10^{8} \mathrm{~T}^{-1} \mathrm{~s}^{-1}$ is the gyromagnetic ratio of the ${ }^{1} \mathrm{H}$ nucleus, $\delta=2 \mathrm{~ms}$ is the duration of the field gradient pulse, $\Delta=100 \mathrm{~ms}$ is the time period between the two field gradient pulses, and $\mathrm{g}$ is the amplitude of the field gradient pulse.

Figure 2 shows the signal attenuation and the selfdiffusion coefficients for five peaks corresponding to $\mathrm{Pk} 2$, Pk4, Pk5, Pk6 (SDS1, SDS2, SDS3, SDS4), and Pk3 (PEO). It is clear from Fig. 2 that the signal attenuation is monoexponential for all peaks over the whole range of SDS concentration. The values of the self-diffusion coefficients $D$ for different molecules were calculated from the slopes of the curves in Fig. 2. The gradient pulse duration was $\delta=2 \mathrm{~ms}$,

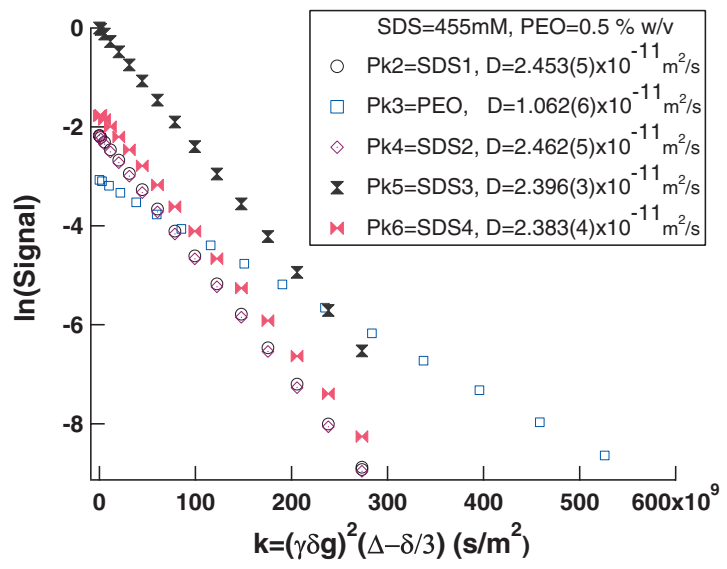

FIG. 2. The attenuation of the signal $\mathrm{S}(\mathrm{k}) / \mathrm{S}(0)$ on a $\log$ scale vs $\mathrm{k}$ $=(\gamma \delta g)^{2}(\Delta-\delta / 3)$ for $\mathrm{PEO}(0.5 \% \mathrm{w} / \mathrm{v}) / \mathrm{SDS}(455 \mathrm{mM}) / \mathrm{D}_{2} \mathrm{O}$ sample with $\delta$ $=2 \times 10^{-3} \mathrm{~s}, \Delta=100 \times 10^{-3} \mathrm{~s}$. while the time period between the gradient pulses was $\Delta$ $=100 \mathrm{~ms}$. The gradient pulse strength $\mathrm{g}$ was increased in a linear sequence of 16 steps up to $480 \mathrm{G} / \mathrm{cm}$ for PEO diffusion, while for SDS diffusion $\mathrm{g}$ was increased in a linear sequence of 16 steps up to $350 \mathrm{G} / \mathrm{cm}$.

The relaxation measurements were performed using a Bruker high resolution (TXI) probe. The inversion recovery technique was used to measure $\mathrm{T}_{1}$ : eight time delays were used to measure $\mathrm{T}_{1}$ for the PEO peak region, and the intensity data were fitted to the equation $\mathrm{I}(\mathrm{t})=\mathrm{I}_{\mathrm{o}}(1$ $\left.-2 \exp \left(-\mathrm{t} / \mathrm{T}_{1}\right)\right) .{ }^{37} \mathrm{~A}(\pi / 2)_{\mathrm{x}}-\mathrm{t}-(\pi)_{\mathrm{x}}-\mathrm{t}$-acquire spin echo experiment was used to measure $\mathrm{T}_{2}: 16$ values, at delay times $t$, of the integrated intensity of the PEO peak were taken to measure $T_{2}$ and the intensity data were fitted to the equation $\mathrm{I}(\mathrm{t})=\mathrm{I}_{\mathrm{o}} \exp \left(-\mathrm{t} / \mathrm{T}_{2}\right){ }^{37}$

\section{RESULTS AND DISCUSSION}

\section{A. Chemical shift measurements}

Chemical shift studies are a well-established method to characterize critical concentrations. ${ }^{29,38}$ Figure 3(a) shows the variation in the chemical shift difference between the protons of SDS1 and SDS4 chemical groups for each
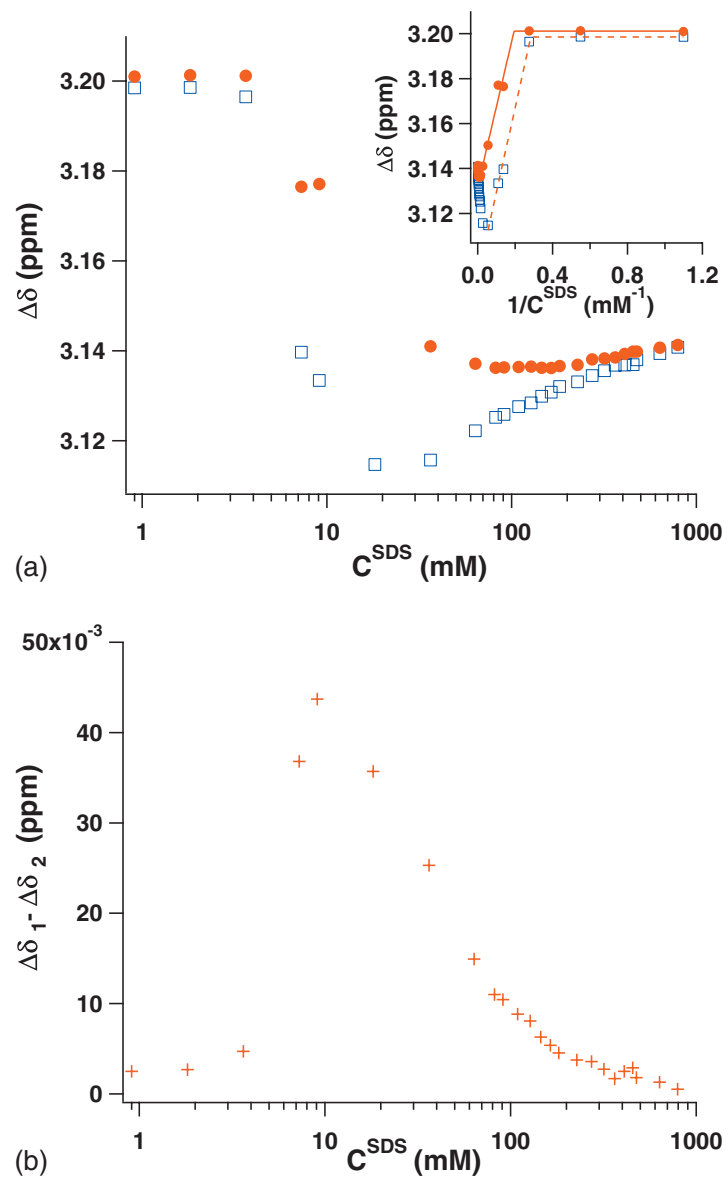

FIG. 3. (a) Chemical shift difference $(\Delta \delta)$ between the protons of SDS1 and SDS4 for each $\mathrm{PEO}(0.5 \% \mathrm{w} / \mathrm{v}) / \mathrm{SDS} / \mathrm{D}_{2} \mathrm{O}$ (opened squares) and $\mathrm{SDS} / \mathrm{D}_{2} \mathrm{O}$ (solid circles) sample vs SDS concentration. Inset: $\Delta \delta$ vs reciprocals of SDS concentrations. (b) The difference in the value of $\Delta \delta$ between SDS $/ \mathrm{D}_{2} \mathrm{O}$ samples $\left(\Delta \delta_{1}\right)$ and $\mathrm{PEO}(0.5 \% \mathrm{w} / \mathrm{v}) / \mathrm{SDS} / \mathrm{D}_{2} \mathrm{O}$ samples $\left(\Delta \delta_{2}\right)$ vs SDS concentration. The difference between PEO-SDS and pure SDS solutions is greatest between $\approx 4$ and $100 \mathrm{mM}$. 
$\mathrm{SDS} / \mathrm{D}_{2} \mathrm{O}$ and $\mathrm{PEO}(0.5 \% \mathrm{w} / \mathrm{v}) / \mathrm{SDS} / \mathrm{D}_{2} \mathrm{O}$ sample over the whole range of SDS concentration. The chemical shift difference is sensitive to the average local environment of the SDS molecule. Assuming fast chemical exchange, the observed chemical shift is a weighted average of the SDS in free and in micellar form. Below the CMC/CAC, this results [see Gao, Wasilyshen, and Kwak, ${ }^{38}$ Eq. (1), and Cui et al. ${ }^{27}$ ] in a reciprocal relationship between the observed chemical shift and the total SDS concentration. In particular,

$$
\begin{aligned}
& \delta_{\text {Obs }}=\delta_{\text {free }}, \quad \mathrm{C}^{\mathrm{SDS}} \leq \mathrm{C}^{*}, \\
& \delta_{\mathrm{Obs}}=\left(\frac{\mathrm{C}^{*}}{\mathrm{C}^{\mathrm{SDS}}}\right) \delta_{\text {free }}+\left(1-\frac{\mathrm{C}^{*}}{\mathrm{C}^{\mathrm{SDS}}}\right) \delta^{*}, \quad \mathrm{C}^{\mathrm{SDS}}>\mathrm{C}^{*},
\end{aligned}
$$

where $\mathrm{C}^{*}$ denotes $\mathrm{CMC}$ or $\mathrm{CAC}$ and $\delta^{*}$ denotes $\delta_{\text {micelle }}$ or $\delta_{\text {aggregate }}$ for $\mathrm{SDS} / \mathrm{D}_{2} \mathrm{O}$ or $\mathrm{PEO}(0.5 \% \mathrm{w} / \mathrm{v}) / \mathrm{SDS} / \mathrm{D}_{2} \mathrm{O}$, respectively.

By linear fitting, a plot of the chemical shift difference against $1 / \mathrm{C}^{\mathrm{SDS}}$ using the piecewise function in Eq. (2) [Fig. 3(a), inset], we obtained the critical micelle concentration $[\mathrm{CMC}=5.1(4) \mathrm{mM}]$ and the critical aggregation concentration $[\mathrm{CAC}=3.5(1) \mathrm{mM}]$.

The SDS1 group is more susceptible to the extramicellar environment than SDS4 group. A lower $\Delta \delta$ [e.g., Fig. 3(a)] indicates better shielding of the SDS1 group. This indicates that for a fixed C $C^{S D S}$, the SDS1 group is better shielded in the presence of PEO.

Figure 3(b) shows the variation in the difference in the value of $\Delta \delta$ for $\mathrm{SDS} / \mathrm{D}_{2} \mathrm{O}$ samples $\left(\Delta \delta_{1}\right)$ and the corresponding $\left(\Delta \delta_{2}\right)$ for $\mathrm{PEO}(0 . \% \mathrm{w} / \mathrm{v}) / \mathrm{SDS} / \mathrm{D}_{2} \mathrm{O}$ samples. The difference $\left(\Delta \delta_{1}-\Delta \delta_{2}\right)$ reports on the effect of PEO on the local environment of SDS at any given concentration. This difference is smallest at very low $(<3 \mathrm{mM})$ and at very high $(>400 \mathrm{mM})$ SDS concentration and largest at $10 \mathrm{mM}$.

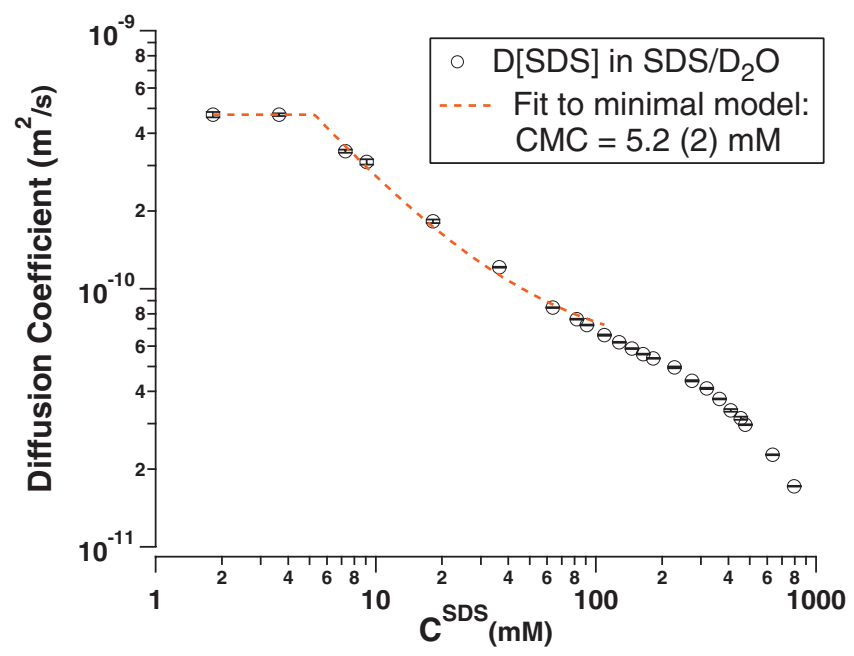

FIG. 4. SDS self-diffusion coefficient in SDS/ $\mathrm{D}_{2} \mathrm{O}$ vs SDS concentration. Error bars smaller than the symbol size. The fit to the minimal model breaks down above $\approx 100 \mathrm{mM}$ due to obstruction effects (see text).
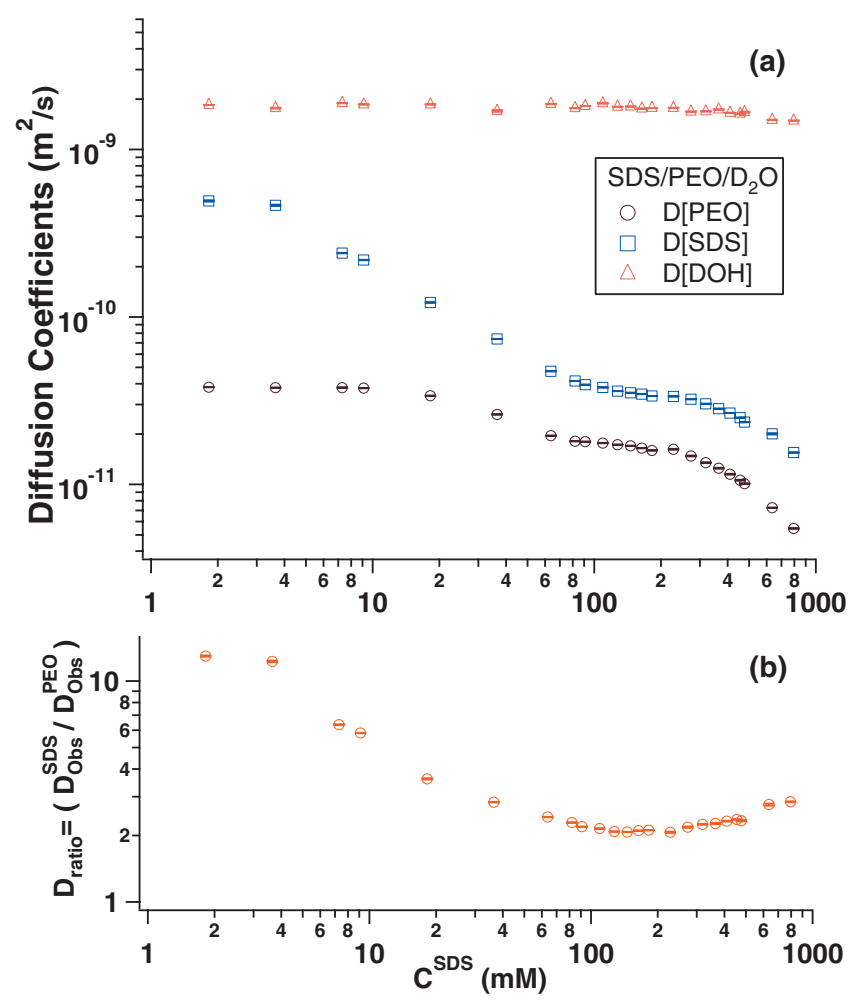

FIG. 5. (a) Self-diffusion coefficient of PEO, SDS, and DOH in $\mathrm{PEO}(0.5 \% \mathrm{w} / \mathrm{v}) / \mathrm{SDS} / \mathrm{D}_{2} \mathrm{O}$ vs SDS concentration. (b) Ratio of SDS selfdiffusion coefficient $\left(\mathrm{D}_{\mathrm{Obs}}^{\mathrm{SDS}}\right)$ to PEO self-diffusion coefficient $\left(\mathrm{D}_{\mathrm{Obs}}^{\mathrm{PEO}}\right)$. Error bars are smaller than the symbol size.

\section{B. Self-diffusion measurements}

We have prepared 20 samples each of $\mathrm{SDS} / \mathrm{D}_{2} \mathrm{O}$ and $\mathrm{SDS} / \mathrm{PEO} / \mathrm{D}_{2} \mathrm{O}$ with constant $\mathrm{PEO}$ concentration of $0.5 \%$ $\mathrm{w} / \mathrm{v}$ at different $\mathrm{SDS}$ concentrations $\left(\mathrm{C}^{\mathrm{SDS}}\right)$.

Figure 4 shows the self-diffusion coefficient of SDS in a solution of $\mathrm{SDS} / \mathrm{D}_{2} \mathrm{O}$ (no polymer). For $\mathrm{C}^{\mathrm{SDS}}<100 \mathrm{mM}$ we can fit the self-diffusion coefficient curve of SDS in $\mathrm{SDS} / \mathrm{D}_{2} \mathrm{O}$ solution; the model used is described in the discussion. From this fit, the value of CMC agrees well with the value obtained from the chemical shift measurements [e.g., Fig. 3(a)].

Figure 5(a) shows the self-diffusion coefficient of SDS, $\mathrm{PEO}$, and $\mathrm{DOH}$ in $\mathrm{SDS}\left(794 \mathrm{mM} / \mathrm{PEO}(0.5 \% \mathrm{w} / \mathrm{v}) / \mathrm{D}_{2} \mathrm{O}\right.$. The self-diffusion coefficient of SDS in SDS $/ \mathrm{PEO} / \mathrm{D}_{2} \mathrm{O}$ remains constant up to about $\mathrm{C}^{\mathrm{SDS}}=3.5 \mathrm{mM}$.

On the other hand, the self-diffusion coefficient curve of PEO begins to exhibit a noticeable decrease only at a higher value of $\operatorname{SDS}$ concentration $(\approx 10 \mathrm{mM})$. This behavior is consistent with SDS molecules associating with PEO. The effect of this association should affect the dynamics of the smaller SDS molecule more strongly than it affects the much larger polymer chain. ${ }^{19}$ Upon increasing the SDS concentration, the diffusion coefficient of both PEO and SDS decreases sharply for $\mathrm{C}^{\mathrm{SDS}}<100 \mathrm{mM}$. For $\mathrm{C}^{\mathrm{SDS}}>100 \mathrm{mM}$, the SDS and PEO diffusion coefficients show a slower functional dependence on SDS concentration, and both curves in this regime have a remarkably similar shape (the ratio of observed SDS and PEO diffusion coefficients is not constant above $100 \mathrm{mM}$, but the variation is much weaker). 


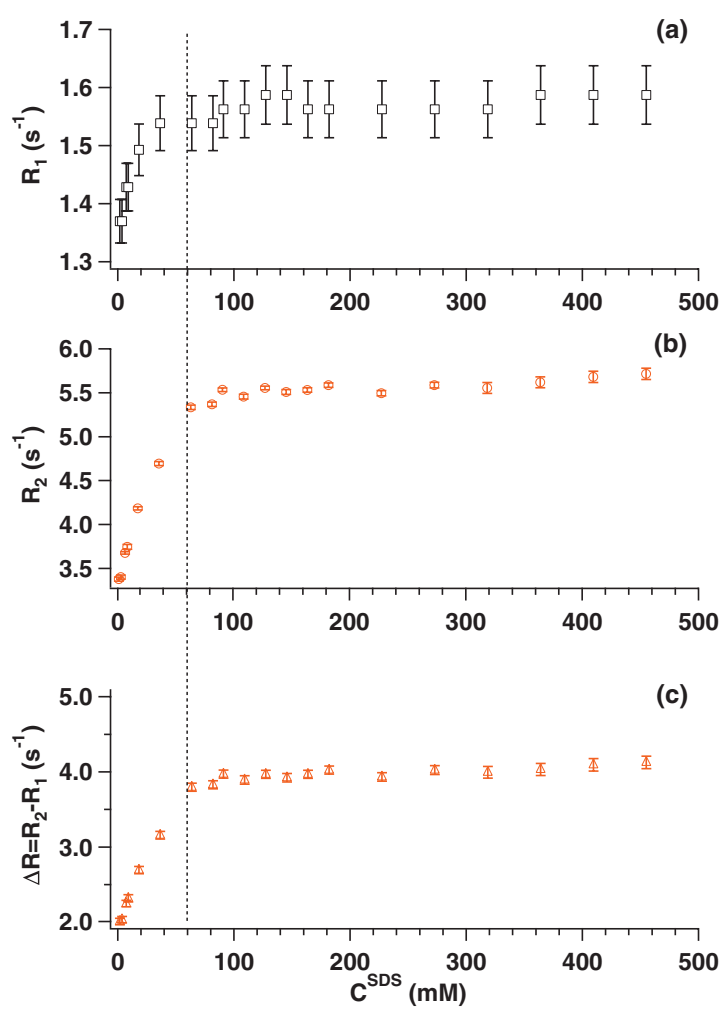

FIG. 6. (a) Proton longitudinal relaxation rates $\mathrm{R}_{1}$, (b) transverse relaxation rates $R_{2}$, and (c) the difference $\Delta R=R_{2}-R_{2}$ for PEO vs SDS concentration.

\section{Relaxation measurements}

According to the two-step model for relaxation in surfactant systems, ${ }^{32,39-41}$ both the proton longitudinal relaxation rate $R_{1}$ and the transverse relaxation rate $R_{2}$ at different SDS concentrations are sensitive to fast local motions ("free state") as well as slower aggregate motions ("aggregate state"). The difference $\Delta \mathrm{R}=\mathrm{R}_{2}-\mathrm{R}_{1}$ reports ${ }^{41}$ on the slower (aggregate) motions.

Longitudinal $T_{1}$ and transverse $T_{2}$ relaxation measurements were made for the PEO peak at different SDS concentration. Figure 6 shows the variation in proton longitudinal relaxation rates $\mathrm{R}_{1}=1 / \mathrm{T}_{1}$ [e.g., Fig. 6(a)], transverse relaxation rates $R_{2}=1 / T_{2}$ [e.g., Fig. $\left.6(b)\right]$, and the difference $\Delta \mathrm{R}=\mathrm{R}_{2}-\mathrm{R}_{1}$ [e.g., Fig. 6(c)] for PEO molecule at different SDS concentrations.

The relaxation rates measurements share a characteristic of a plateau above $60 \mathrm{mM}$, which coincides roughly with what we observe from the diffusion measurements. It represents an onset of the regime at which PEO chains saturate with SDS molecules. As has been noted before, ${ }^{41}$ the interpretation of NMR relaxation data is somewhat more involved than that of NMR diffusion data. We thus use the polymer relaxation rate measurements only as independent confirmation of the diffusometry results.

\section{Discussion}

We begin by discussing the chemical shift results. Below the $\mathrm{CAC}$ and $\mathrm{CMC}$, respectively, the chemical shift difference between the SDS4 and SDS1 group (representing difference in shielding between the group least and most proxi- mate to the $\mathrm{SO}_{4}^{-}$ion) is $\approx 3.2 \mathrm{ppm}$ for both pure SDS and the SDS-PEO system. At a given $\mathrm{C}^{\mathrm{SDS}}$, the difference $\Delta \delta_{1}$ $-\Delta \delta_{2}$ represents the difference in the chemical environment due solely to the presence of the polymer. The difference is maximum at about $10 \mathrm{mM}$ and decreases continuously for large $\mathrm{C}^{\mathrm{SDS}}$.

Next we discuss the diffusion results, beginning with the most dilute samples. From the SDS diffusion at the lowest SDS concentration (e.g., Figs. 4 and 5), we note no difference here due to the presence of PEO. We estimate the corresponding hydrodynamic radius $R_{H}$ /radius of gyration $R_{G}$ using the values of the SDS and PEO diffusion coefficients at the lowest SDS concentration and the relevant forms of the Sutherland-Stokes-Einstein equation ${ }^{19}$

$$
\mathrm{R}_{\mathrm{H}}=\frac{\mathrm{K}_{\mathrm{B}} \mathrm{T}}{6 \pi \eta \mathrm{D}}, \quad \mathrm{R}_{\mathrm{G}}=\frac{\mathrm{R}_{\mathrm{H}}}{0.7},
$$

where $\mathrm{K}_{\mathrm{B}}$ is the Boltzmann's constant, $\mathrm{T}$ is the absolute temperature, and $\eta$ is the solvent viscosity $\left(\eta_{\mathrm{D}_{2} \mathrm{O}} \approx 1.1 \mathrm{mPa} \mathrm{s}\right)$. For the SDS molecule this yields a hydrodynamic radius $\mathrm{R}_{\mathrm{H}}$ is $\approx 4.01(3) \mathrm{A}^{\circ}$. This is comparable to the hydrodynamic radius of $3.9 \mathrm{~A}^{\circ}$ of an all-trans $\mathrm{N}=12$ carbon chain. The hydrodynamic radius is defined as $\left(1 / \mathrm{R}_{\mathrm{H}}\right)$ $=\left(1 / \mathrm{N}^{2}\right) \sum_{i, j=1, i \neq j}^{N}\left\langle\frac{1}{\mathrm{r}_{\mathrm{ij}}}\right\rangle$, where $\mathrm{r}_{\mathrm{ij}}$ is the distance between sites $\mathrm{i}$ and $\mathrm{j}$ on the chain, e.g., see Yethiraj. ${ }^{42} \mathrm{We}$ also obtain the radius of gyration of the $\mathrm{PEO}$ molecule $\mathrm{R}_{\mathrm{G}}$ is $\approx 7.43(1) \mathrm{nm}$. This agrees with the calculated value in the previous studies. ${ }^{19}$

The concentration of free surfactant above the CMC in $\mathrm{SDS} / \mathrm{D}_{2} \mathrm{O}$ solutions is expected to be constant $\left(\mathrm{C}_{\text {free }}^{\mathrm{SDS}}\right.$ $=\mathrm{CMC}$ ), while below the CMC the concentration of free surfactant equals the total concentration of surfactant, $\mathrm{C}_{\text {free }}^{\mathrm{SDS}}$ $=\mathrm{C}^{\mathrm{SDS}}$. The standard minimal model for the pure surfactant system is thus

$$
\begin{aligned}
& \mathrm{D}_{\mathrm{Obs}}^{\mathrm{SDS}}=\mathrm{D}_{\text {free }}^{\mathrm{SDS}}, \quad \mathrm{C}^{\mathrm{SDS}} \leq \mathrm{CMC}, \\
& \mathrm{D}_{\mathrm{Obs}}^{\mathrm{SDS}}=\left(\frac{\mathrm{CMC}}{\mathrm{C}^{\mathrm{SDS}}}\right) \mathrm{D}_{\text {free }}^{\mathrm{SDS}}+\left(1-\frac{\mathrm{CMC}}{\mathrm{C}^{\mathrm{SDS}}}\right) \mathrm{D}_{\text {micelle }}^{\mathrm{SDS}}, \\
& \mathrm{C}^{\mathrm{SDS}}>\mathrm{CMC} .
\end{aligned}
$$

We assume $\mathrm{D}_{\text {micelle }}^{\mathrm{SDS}}$ is constant for small enough SDS concentrations. Fitting to the above model we obtain a good fit for $\mathrm{C}^{\mathrm{SDS}}<100 \mathrm{mM}$ (e.g., Fig. 4), yielding the following parameters: $\quad \mathrm{D}_{\text {free }}^{\mathrm{SDS}}=4.7(1) \times 10^{-10} \mathrm{~m}^{2} / \mathrm{s}, \quad \mathrm{D}_{\text {micelle }}^{\mathrm{SDS}}=6.0(9)$ $\times 10^{-11} \mathrm{~m}^{2} / \mathrm{s}$, and $\mathrm{CMC}=5.2(2) \mathrm{mM}$. The CMC thus obtained is consistent with value obtained from the chemical shift results [e.g., Fig. 3(a)]. For surfactant-polymer aggregates, the situation is more complicated because aggregate size is expected to change a lot. Because the pulsed-fieldgradient signal attenuation is monoexponential, we conclude that the exchange of SDS molecules between the SDS-PEO in aggregates and in free solution must be very rapid on the NMR time scale. Thus, we postulate a minimal (two species: free SDS and SDS in an aggregate) model: that the observed self-diffusion coefficients for SDS is a linear combination of the self-diffusion coefficient of the free molecules in bulk 


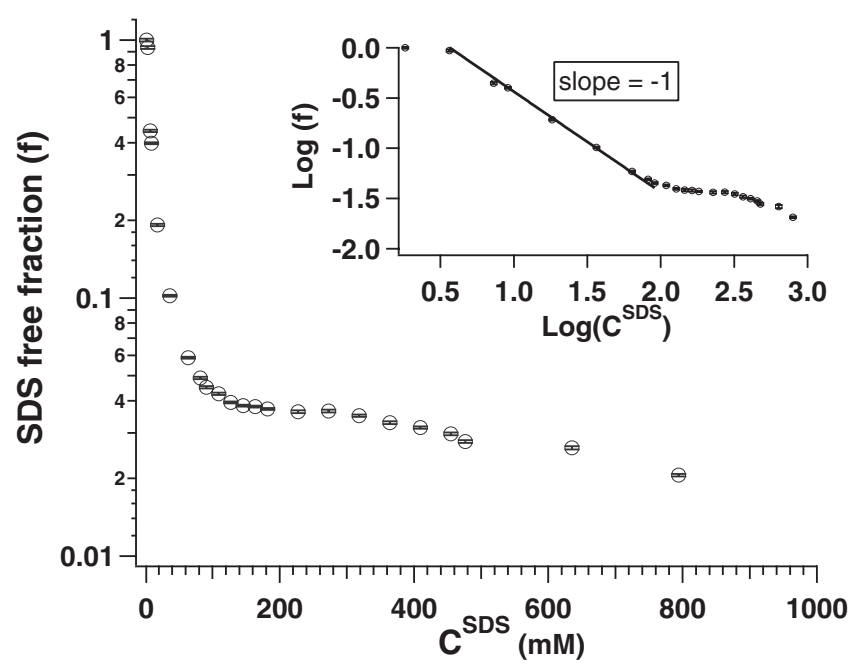

FIG. 7. SDS free fraction $f$ vs SDS concentration. Inset: A log-log plot yields a slope of -1 for $3.5 \mathrm{mM}<\mathrm{C}^{\mathrm{SDS}}<60 \mathrm{mM}$. Error bars smaller are than symbol size.

solution and that of the bound molecules associated with the complexes $^{19,25}$

$$
\mathrm{D}_{\text {Obs }}^{\mathrm{SDS}}=\mathrm{fD}_{\text {free }}^{\mathrm{SDS}}+(1-\mathrm{f}) \mathrm{D}_{\text {aggregate }}^{\mathrm{SDS}},
$$

where $\mathrm{f}$ is fraction of free surfactant in the monomer state in the aqueous solution, and $\mathrm{D}_{\text {free }}^{\mathrm{SDS}}$ and $\mathrm{D}_{\text {aggregate }}^{\mathrm{SDS}}$ are the selfdiffusion coefficient of free SDS molecules (free "monomers" in the bulk solution) and the SDS species associated with the polymer, respectively. Since we know that there is unlikely to be free PEO, we assume that $\mathrm{D}_{\text {aggregate }}^{\text {SDS }}$ in Eq. (5) is identical to the observed PEO diffusion coefficient $\mathrm{D}_{\mathrm{Obs}}^{\mathrm{PEO}}$,

$$
\mathrm{D}_{\mathrm{Obs}}^{\mathrm{SDS}}=\mathrm{fD}_{\text {free }}^{\mathrm{SDS}}+(1-\mathrm{f}) \mathrm{D}_{\mathrm{Obs}}^{\mathrm{PEO}} \text {. }
$$

In the intermediate $\left(\mathrm{C}^{\mathrm{SDS}}>100 \mathrm{mM}\right)$ regime, we note that the functional form of the SDS and the PEO diffusion coefficients are remarkably similar [e.g., Fig. 5(a)]. However a close look at the ratio $\mathrm{D}_{\mathrm{Obs}}^{\mathrm{SDS}} / \mathrm{D}_{\mathrm{Obs}}^{\mathrm{PEO}}$ [e.g., Fig. 5(b)] shows a minimum just above $100 \mathrm{mM}$, and then a small steady increase. Using Eq. (6) we calculate the SDS free fraction over the entire range of SDS concentration. This is shown in Fig. 7.

We can see clearly from Fig. 7 that the fraction of free SDS in the bulk solution starts decreasing rapidly at the CAC up to $\approx 100 \mathrm{mM}$, where about $4 \%$ of free SDS is available in the bulk solution. At the highest SDS concentration (where a transition to rodlike micelles is thought to take place) the free SDS fraction $\mathrm{f} \approx 2 \%$. In addition, the functional dependence of the free SDS fraction $f$ on SDS concentration $C^{S D S}$ shows linear behavior in the regime where charged SDSPEO aggregates are expected start forming: $\log (\mathrm{f})$ $=-\log \left(\mathrm{C}^{\mathrm{SDS}}\right)+0.56(1)$. Thus, $\mathrm{f} \propto 1 / \mathrm{C}^{\mathrm{SDS}}$ in this concentration range. In Fig. 8, we therefore plot the concentration of free $\mathrm{SDS}, \mathrm{C}_{\mathrm{f} 2}=\mathrm{fC}^{\mathrm{SDS}}$. The concentration of free SDS molecules $\mathrm{C}_{\mathrm{f} 2}$ in the $3.5-60 \mathrm{mM}$ range is almost constant. Fitting this range to a flat line represents an accurate way to estimate the value of $\mathrm{CAC}$ : $\mathrm{CAC}=\mathrm{C}_{\text {free }}^{\mathrm{SDS}}=3.53(8) \mathrm{mM}$. This is the most precise method to determine the $\mathrm{CAC}$ that we know of. This result is not consistent with surfactant-specific electrode data $^{43}$ that suggest that the free SDS concentration is not

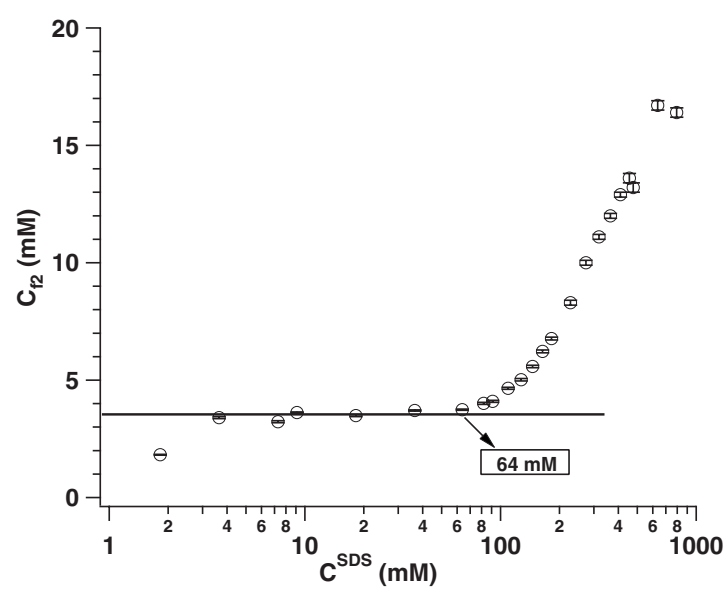

FIG. 8. Minimal two-specie model: the dependence of the concentration of free SDS $\mathrm{C}_{\mathrm{f} 2}$ on the total SDS concentration. Error bars smaller are than symbol size.

constant in this region. Interpretation of these latter results above the CAC, however, involves an additional calibration procedure. The diffusometry results for SDS-PEO solutions are very analogous to what is expected for pure SDS solutions, where the SDS monomer concentration reaches a plateau value that is close to the $\mathrm{CMC}{ }^{26}$

Samples at concentrations above the one at $64 \mathrm{mM}$ exhibit a sharp increase in $\mathrm{C}_{\mathrm{f} 2}$ (e.g., Fig. 8). The sharp increase in $\mathrm{C}_{\mathrm{f} 2}$ is clearly not physical. The minimal model for the pure SDS system implies that the free SDS concentrations never exceeds the CMC. We may thus assume that all the excess in the $\mathrm{PEO} / \mathrm{SDS} / \mathrm{D}_{2} \mathrm{O}$ system is actually in the form of free micelles. If we denote the total concentration when the free SDS concentration reaches CMC as $\mathrm{C}_{\mathrm{m}}$, then clearly the two-specie model, which is valid below $\mathrm{C}_{\mathrm{m}}$, breaks down above $\mathrm{C}_{\mathrm{m}}$. Thus our minimal three-specie model is summarized as follows:

$$
\begin{aligned}
\mathrm{D}_{\mathrm{Obs}}^{\mathrm{SDS}}= & \left(\frac{\mathrm{C}_{\mathrm{f} 3, \text { monomer }}}{\mathrm{C}^{\mathrm{SDS}}}\right) \mathrm{D}_{\text {free }}^{\mathrm{SDS}}+\left(\frac{\mathrm{C}_{\mathrm{f} 3 \text {, aggregate }}}{\mathrm{C}^{\mathrm{SDS}}}\right) \mathrm{D}_{\mathrm{Obs}}^{\mathrm{PEO},} \\
\mathrm{C}^{\mathrm{SDS}} \leq & \mathrm{C}_{\mathrm{m}}, \\
\mathrm{D}_{\mathrm{Obs}}^{\mathrm{SDS}}= & \left(\frac{\mathrm{CMC}}{\mathrm{C}^{\mathrm{SDS}}}\right) \mathrm{D}_{\text {free }}^{\mathrm{SDS}}+\left(\frac{\mathrm{C}_{\mathrm{f} 3 \text {,micelle }}}{\mathrm{C}^{\mathrm{SDS}}}\right) \mathrm{D}_{\text {micelle }}^{\mathrm{SDS}} \\
& +\left(\frac{\mathrm{C}_{\mathrm{f} 3, \text { aggregate }}}{\mathrm{C}^{\mathrm{SDS}}}\right) \mathrm{D}_{\mathrm{Obs}}^{\mathrm{PEO}}, \quad \mathrm{C}^{\mathrm{SDS}}>\mathrm{C}_{\mathrm{m}},
\end{aligned}
$$

where $\mathrm{C}_{\mathrm{f} 3 \text {,monomer }}$ is the concentration of free SDS molecules and $\mathrm{C}_{\mathrm{f} 3 \text {, micelle }}$ is the concentration of free SDS micelles, and

$$
\begin{aligned}
& \mathrm{C}_{\mathrm{f} 3, \text { aggregate }}[\mathrm{mM}]=\mathrm{C}^{\mathrm{SDS}}-\mathrm{C}_{\mathrm{f} 3 \text {, monomer }}, \quad \mathrm{C}^{\mathrm{SDS}} \leq \mathrm{C}_{\mathrm{m}}, \\
& \mathrm{C}_{\mathrm{f} 3 \text {,aggregate }}[\mathrm{mM}]=\mathrm{C}^{\mathrm{SDS}}-\left(\mathrm{CMC}+\mathrm{C}_{\mathrm{f} 3 \text {, micelle }}\right), \\
& \mathrm{C}^{\mathrm{SDS}}>\mathrm{C}_{\mathrm{m}} .
\end{aligned}
$$

From the observed diffusion coefficients $\left(\mathrm{D}_{\text {free }}^{\mathrm{SDS}}, \mathrm{D}_{\mathrm{Obs}}^{\mathrm{SDS}}\right.$, and $\mathrm{D}_{\mathrm{Obs}}^{\mathrm{PEO}}$ ) and having a reasonable estimate $\mathrm{D}_{\text {micelle }}^{\mathrm{SDS}}$ from the pure SDS solutions, we can calculate $\mathrm{C}_{\mathrm{f} 3 \text {, monomer }}$ below $\mathrm{C}_{\mathrm{m}}$ and $\mathrm{C}_{\mathrm{f} 3 \text {,micelle }}$ above $\mathrm{C}_{\mathrm{m}}$. This is depicted in Fig. 9(a). We can 




(a)

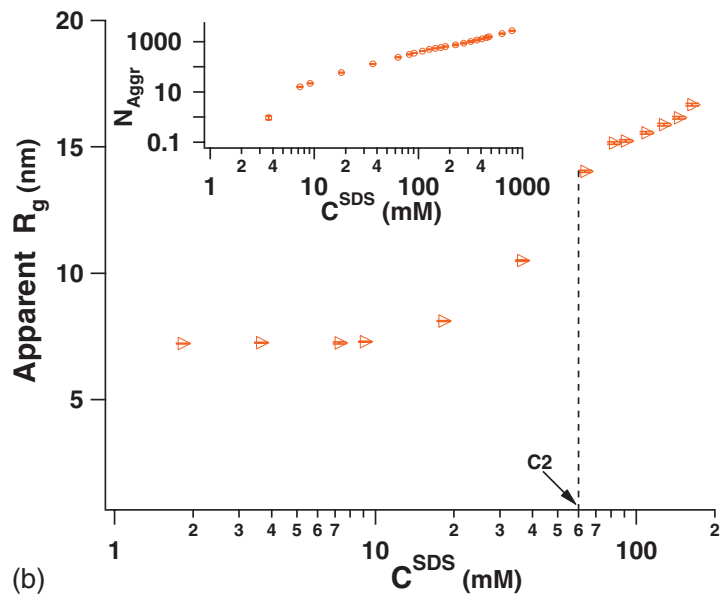

FIG. 9. (a) Three-specie model: the dependence of the concentration of free SDS monomers $\mathrm{C}_{\mathrm{f} 3 \text {,monomer }}$ and free SDS micelles $\mathrm{C}_{\mathrm{f} 3 \text {,micelle }}$ on the total SDS concentration. (b) The apparent radius of gyration of PEO-SDS aggregates $\mathrm{R}_{\mathrm{g}}$ vs SDS concentration. The concentration $\mathrm{C}_{2}$ is shown as a guide. Inset: Number of SDS molecules per PEO molecule in an SDS-PEO aggregate $\mathrm{N}_{\text {Aggr }}$ vs SDS concentration. Error bars smaller are than symbol size.

also estimate the radius of gyration of the PEO-SDS aggregates using Eq. (3) [e.g., Fig. 9(b)]. This is only valid when crowding effects are negligible. This is clearly the case for $\mathrm{C}^{\mathrm{SDS}}<\mathrm{C}_{2} \approx 60 \mathrm{mM}$ when the volume fraction $\Phi$ in a system of pure spherical SDS micelles is $\approx 0.04 ; \mathrm{C}_{2}$ is the concentration where the SDS monomer concentration starts to increase above the plateau CAC value [e.g., Fig. 9(a)], and the polymer relaxation rate has reached a plateau value (e.g., Fig. 6). Figure 9(b) (inset) shows the variation in the average number of SDS molecules $\mathrm{N}_{\text {Aggr }}$ $=\mathrm{C}_{\mathrm{f} 3 \text {, aggregate }}[\mathrm{mM}] / 0.25[\mathrm{mM}]$, where we have used a PEO concentration of $5 \mathrm{mg} / \mathrm{ml}$ and $\mathrm{M}_{\mathrm{w}}=20000$, for a SDS-PEO aggregate over the whole range of SDS concentration.

Fitting model to data yields $\mathrm{C}_{\mathrm{m}} \approx 145 \mathrm{mM}$. The logarithmic increase in $\mathrm{C}_{\mathrm{f} 3 \text {,micelle }}$ above $\mathrm{C}_{\mathrm{m}}$ is consistent with the modest increase in the ratio of observed SDS to PEO diffusion coefficients.

Finally, the top curve in Fig. 5 shows the variation in the measured self-diffusion coefficient of DOH molecule at different SDS concentrations. The DOH self-diffusion coefficient is almost constant for $\mathrm{C}^{\mathrm{SDS}}<100 \mathrm{mM}$ where both $\mathrm{PEO}$ and SDS self-diffusion coefficients are decreasing. For $\mathrm{C}^{\mathrm{SDS}}>100 \mathrm{mM}$ there is a decrease in the DOH self-

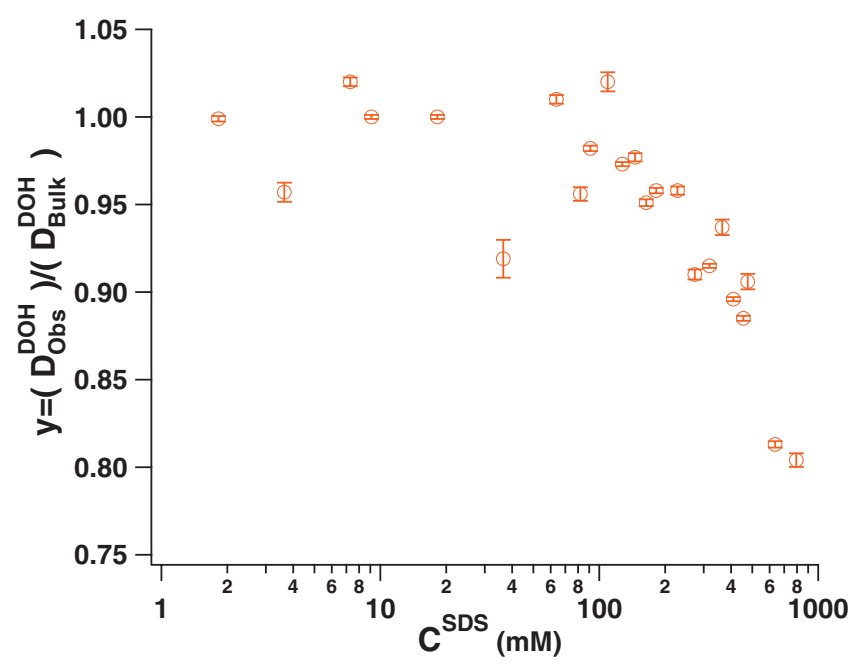

FIG. 10. Relative DOH diffusion coefficient exhibits a noticeable decrease above $\approx 100 \mathrm{mM}$.

diffusion coefficient. This could arise from DOH molecules that associate with the surface of charged SDS micelles or SDS-PEO aggregates, as well as obstruction effects (in a system of pure spherical SDS micelles we estimate the volume fraction to be $\Phi \approx 0.07$ at $\mathrm{C}^{\mathrm{SDS}}=100 \mathrm{mM}$.

Figure 10 shows the variation in $\mathrm{DOH}$ relative diffusion coefficient $y$ as a function of SDS concentration, where

$$
\mathrm{D}_{\mathrm{Obs}}^{\mathrm{DOH}} \approx \mathrm{yD}_{\mathrm{Bulk}}^{\mathrm{DOH}}
$$

We find in this study that there are two distinct concentrations above the CAC.

1. From diffusion measurements, we infer that when the SDS free concentration $\mathrm{C}_{\text {free }}^{\mathrm{SDS}}$ rises above CAC, this indicates the onset of more crowded surfactant environment. We denote this first concentration as $\mathrm{C}_{2}$. This coincides with the crossover concentration for relaxation behavior (e.g., Fig. 6), $\mathrm{C}_{2}=60 \mathrm{mM}$. This corresponds to $\mathrm{N}_{\mathrm{Aggr}} \approx 240$.

2. The ratio of SDS to PEO diffusion coefficients exhibits a minimum at $\approx 100 \mathrm{mM}$. Applying the minimal model [Eq. (7)] to our diffusion results for PEO-SDS yields a critical concentration $\mathrm{C}_{\mathrm{m}} \approx 145 \mathrm{mM}$, above which free micelles must exist. The increase in the ratio of observed SDS and PEO diffusion coefficients above $\mathrm{C}_{\mathrm{m}}$ is therefore simply attributable to the proliferation of free micelles (which are smaller and more mobile the polymer-surfactant aggregate).

The chemical shifts, diffusometry, and relaxometry results present a coherent picture. The SDS monomer concentration saturates at the CAC value, while $\mathrm{N}_{\mathrm{Aggr}}$ (number of SDS molecules aggregated on the polymer) gradually increases. At $\mathrm{C}_{2}$, the increase in SDS monomer concentration is sharp; however, the aggregation number continues to increase. The relatively broad crossover as seen by the polymer is thus consistent with a sharper crossover in the free SDS concentration. 


\section{CONCLUSION}

The study of the molecular dynamics in the SDS-PEO system using the NMR technique gives us an opportunity to make quantitative statements about macromolecular aggregates in a model polymer-surfactant system. The ratio of observed SDS and PEO diffusion coefficients in $\mathrm{PEO}(0.5 \% \mathrm{w} / \mathrm{v}) / \mathrm{SDS} / \mathrm{D}_{2} \mathrm{O}$ solution (e.g., Fig. 5$)$ revealed a sharp decrease below $100 \mathrm{mM}$ followed by a slight increase for $\mathrm{C}^{\mathrm{SDS}}>100 \mathrm{mM}$. Moreover, for $\mathrm{C}^{\mathrm{SDS}}>100 \mathrm{mM}$ the DOH diffusion coefficient decreases, likely indicating an increase in the fraction of water associated with the charged surfactant (e.g., Fig. 10), as well as an increase in obstruction effects.

Relaxation rate difference measurements report on slower aggregate motions. Proton NMR relaxation rate measurements show a clear separation between two regimes of aggregate motions with a crossover at a concentration $\mathrm{C}_{2}$ $=60 \mathrm{mM}$.

We assumed that the observed self-diffusion coefficient for SDS is a linear combination of the self-diffusion coefficient of both free SDS molecules and the polymer-associated SDS molecules below $\mathrm{C}_{2}$ while it includes a third species (free micelles) above $\mathrm{C}_{\mathrm{m}}$. Our analysis revealed that the concentration of free SDS molecules is almost constant $( \pm 3 \%)$ from $3.5 \mathrm{mM}$ up to a concentration $\mathrm{C}_{2}=60 \mathrm{mM}$ (e.g., Fig. 8). Self-consistently, this plateau concentration value coincides with the CAC, giving us additional confidence in the model in this range. Indeed, the average free SDS concentration in this range is a very accurate way to locate the CAC: we obtain a value of $3.53(8) \mathrm{mM}$.

Allowing for a third species (free micelles) when $\mathrm{C}_{\mathrm{f} 3}$ $>\mathrm{CMC}$, we find that $\mathrm{C}_{\mathrm{f} 3 \text {,micelle }}$ increases sharply at $\mathrm{C}^{\mathrm{SDS}}$ $=C_{m}$ [e.g., Fig. 9(a)]. The average number of SDS molecules for each PEO molecule $\mathrm{N}_{\mathrm{Aggr}}$ increases over the entire range of SDS concentration [e.g., Fig. 9(b)], i.e., it never saturates.

We were able to calculate the concentration of free SDS

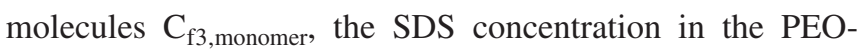

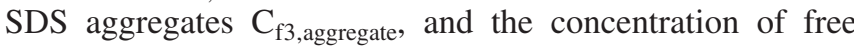
SDS micelles $\mathrm{C}_{\mathrm{f} 3 \text {,micelle }}$ over the entire range of SDS concentration. To summarize:

1. The concentration of free (monomeric) SDS $\mathrm{C}_{\mathrm{f} 3 \text {,monomer }}$ is constant at CAC for a range of total SDS concentrations below $\mathrm{C}_{2}=60 \mathrm{mM}$ (e.g., Fig. 8). We can make a strong statement here: no free micelles exist below $60 \mathrm{mM}$. Above $\mathrm{C}_{2}$, the free monomer concentration

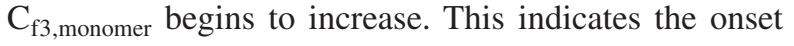
of surfactant crowding environment on the polymer chain. Since the monomer concentration is still below the CMC value for pure SDS solutions, micelles are still not expected.

2. Above $\mathrm{C}_{\mathrm{m}}=145 \mathrm{mM}$, free micelles form [e.g., Fig. 9(a)]. $\mathrm{C}_{\mathrm{f} 3 \text {,monomer }}$ stays at the $\mathrm{CMC}$ for concentrations above $\mathrm{C}_{\mathrm{m}}$, while the concentration of free SDS micelles $\mathrm{C}_{\mathrm{f} 3 \text {,micelle }}$ increases from zero to over $100 \mathrm{mM}$.

3. In the range between $\mathrm{CAC}$ and $\mathrm{C}_{2}$, the chemical environment for the SDS molecules in SDS-PEO solution (as seen from the chemical shift differences labeled in Fig. 3) is maximally different from that at identical concentration in pure SDS solution. This indicates that the SDS conformations in the micelle in pure SDS solution are different from those in the SDS-PEO aggregate (e.g., Fig. 3); in particular, the SDS1 group (closest to the ionic head group of the surfactant) is less well shielded than in the SDS-PEO aggregate. Our NMR results do not provide a more detailed geometric picture of the nature of the aggregates.

4. The PEO-SDS aggregate keeps increasing in size [e.g., Fig. 9(b) and inset]. While $\mathrm{C}_{\mathrm{f} 3 \text {,micelle }}$ increases logarithmically, the number of SDS molecules attached to the aggregate increases roughly linearly with SDS concentration. Our three-specie model is likely an underestimate of the micellar concentration, as it assumes $\mathrm{D}_{\text {micelle }}^{\text {SDS }}$ is a constant (which is an overestimate at higher concentrations due to obstruction effects).

5. There is a clear unambiguous distinction [e.g., Fig. 9(a)] between $C_{2}$ (the onset of surfactant crowding on the polymer chain) and $\mathrm{C}_{\mathrm{m}}$ (the onset of free micelles in solution). This is seen qualitatively from relaxation and diffusion data and quantitatively from fits to a minimal model to interpret the diffusion coefficients.

6. The validity of minimal models is unambiguous and clear below $\mathrm{C}_{2}$. Above $\mathrm{C}_{\mathrm{m}}(\phi \approx 0.1)$, all results [e.g., Figs. 3(b), 4, 9(b), and 10] point to the importance of crowding.

Taken together, our results suggest continuous changes in the aggregation phenomenon over much of the concentration but with three distinct concentrations that signal changes in the nature of the aggregates.

\section{ACKNOWLEDGMENTS}

We are grateful to the Natural Sciences and Engineering Research Council (NSERC) of Canada for financial support of this work. We acknowledge discussions with and technical help from Dr. Celine Schneider.

${ }^{1}$ E. D. Goddard and J. V. Gruber, Principles of Polymer Science and Technology in Cosmetics and Personal Care, 1st ed. (Dekker, New York, 1999).

${ }^{2}$ F. M. Winnik and S. T. A. Regismond, Colloids Surf. 118, 1 (1996).

${ }^{3}$ E. D. Goddard, Colloids Surf. 19, 255 (1986).

${ }^{4}$ D. S. Banks and C. Fradin, Biophys. J. 89, 2960 (2005).

${ }^{5}$ R. J. Ellis, Curr. Opin. Struct. Biol. 11, 114 (2001).

${ }^{6}$ J. Szymański, A. Patkowski, A. Wilk, P. Garstecki, and R. Holyst, J. Phys. Chem. B 110, 25593 (2006).

${ }^{7}$ M. Weiss, M. Elsner, F. Kartberg, and T. Nilsson, Biophys. J. 87, 3518 (2004).

${ }^{8}$ P. Bernadó, J. G. de la Torre, and M. Pons, J. Mol. Recognit. 17, 397 (2004).

${ }^{9}$ K. Chari, J. Kowalczyk, and J. Lal, J. Phys. Chem. B 108, 2857 (2004).

${ }^{10}$ K. Chari, B. Antalek, and J. Minter, Phys. Rev. Lett. 74, 3624 (1995).

${ }^{11}$ H. Evertsson, S. Nilsson, C. J. Welch, and L.-O. Sundelof, Langmuir 14, 6403 (1998)

${ }^{12}$ M. I. Gjerde, W. Nerdal, and H. Hoiland, J. Colloid Interface Sci. 197, 191 (1998).

${ }^{13}$ B. Cabane and R. Duplessix, J. Phys. (Paris) 43, 1529 (1982).

${ }^{14}$ M. de Fatima Carvalho Costa, S. Jose Froehner, A. A. Ruzza, S. de Fatima Santos, and D. Zanette, Quim. Nova 21, 272 (1998).

${ }^{15}$ F. Asaro, L. Feruglio, and G. Pellizer, Colloids Surf., A 245, 127 (2004).

${ }^{16}$ J. Francois, J. Dayantis, and J. Sabbadin, Eur. Polym. J. 21, 165 (1985).

${ }^{17}$ L. Bernazzani, S. Borsacchi, D. Catalano, P. Gianni, V. Mollica, M. Vitelli, F. Asora, and L. Feruglio, J. Phys. Chem. B 108, 8960 (2004). 
${ }^{18}$ H. Z. Yuan, L. Luo, L. Zhang, S. Zhao, S. Z. Mao, J. Y. Yu, L. F. Shen, and Y. R. Du, Colloid Polym. Sci. 280, 479 (2002).

${ }^{19}$ E. Pettersson, D. Topgaard, P. Stilbs, and O. Soderman, Langmuir 20, 1138 (2004).

${ }^{20}$ E. Minatti and D. Zanette, Colloids Surf., A 113, 237 (1996).

${ }^{21}$ M. I. Gjerde, W. Nerdal, and H. Hoiland, J. Colloid Interface Sci. 183 , 285 (1996).

${ }^{22}$ E. S. de Alvarenga, C. F. Lima, and A. M. L. Denadai, Z. Naturforsch. 59a, 291 (2004).

${ }^{23}$ K. Chari, B. Antalek, M. Y. Lin, and S. K. Shin, J. Chem. Phys. 100, 5294 (1994)

${ }^{24}$ J. Zhao and B. M. Fung, Langmuir 9, 1228 (1993).

${ }^{25}$ M. I. Gjerde, W. Nerdal, and H. Hoiland, Colloid Polym. Sci. 276, 503 (1998).

${ }^{26}$ J. N. Israelachvili, Intermolecular and Surface Forces, 2nd ed. (Academic, London, 1992).

${ }^{27}$ X. Cui, S. Mao, M. Liu, H. Yuan, and Y. Du, Langmuir 24, 10771 (2008).

${ }^{28}$ M. Bergström and J. S. Pederson, Phys. Chem. Chem. Phys. 1, 4437 (1999).

${ }^{29}$ B. Cabane, J. Phys. Chem. 81, 1639 (1977).

${ }^{30}$ R. Nagarajan, C. Drew, and C. M. Mello, J. Phys. Chem. C 111, 16105 (2007).
${ }^{31}$ M. Nydén and K. Holmberg, Curr. Opin. Colloid Interface Sci. 14, 169 (2009).

${ }^{32}$ J. M. Landry, D. G. Marangoni, D. A. Arden, I. J. MacLennan, and J. C. T. Kwak, J. Surfactants Deteg. 12, 155 (2009).

${ }^{33}$ W. S. Price, Concepts Magn. Reson. 9, 299 (1997).

${ }^{34}$ C. S. Johnson, Prog. Nucl. Magn. Reson. Spectrosc. 34, 203 (1999).

${ }^{35}$ M. Shi-Zhen and D. You-Ru, Acta Phys.-Chim. Sin. 19, 675 (2003).

${ }^{36}$ W. C. K. Poon and D. Andelman, Soft Condensed Matter Physics in Molecular and Cell Biology, 1st ed. (CRC Press, Taylor and Francis Group, Boca Raton, 2006).

${ }^{37}$ J. Keeler, Understanding NMR Spectroscopy, 1st ed. (Wiley, Chichester, 2005).

${ }^{38}$ Z. Gao, R. E. Wasylishen, and J. C. T. Kwak, J. Colloid Interface Sci. 137, 137 (1990).

${ }^{39}$ H. Wennerstroem, B. Lindman, O. Soderman, T. Drakenberg, and J. B. Rosenholm, J. Am. Chem. Soc. 101, 6860 (1979).

${ }^{40}$ R. E. Wasylishen, J. C. T. Kwak, Z. Gao, E. Verpoorte, J. B. Macdonald, and R. M. Dickson, Can. J. Chem. 69, 822 (1991).

${ }^{41}$ O. Söderman, P. Stilbs, and W. S. Price, Concepts Magn. Reson. 23A, 121 (2004).

${ }^{42}$ A. Yethiraj, J. Chem. Phys. 125, 204901 (2006).

${ }^{43}$ S. M. Ghoreishi, Y. Li, D. M. Bloor, J. Warr, and E. Wyn-Jones, Langmuir 15, 4380 (1999). 